\title{
Association of ATP7A expression and in vitro sensitivity to cisplatin in non-small cell lung cancer
}

\author{
YOSHIMASA INOUE ${ }^{1}$, HOZUMI MATSUMOTO ${ }^{2}$, SHUNSUKE YAMADA ${ }^{3}$, KENJI KAWAI $^{2}$, HIROSHI SUEMIZU $^{2}$, \\ MASATOSHI GIKA ${ }^{4}$, IWAO TAKANAMI ${ }^{5}$, MASAYUKI IWAZAKI ${ }^{6}$ and MASATO NAKAMURA ${ }^{2,7}$ \\ ${ }^{1}$ Department of General Thoracic Surgery, Ikegami General Hospital, Ota-ku, Tokyo 146-8531; \\ ${ }^{2}$ Central Institute for Experimental Animals, Kawasaki, Kanagawa 216-0003; ${ }^{3}$ Department of General Thoracic Surgery, \\ Tokai University Hachioji Hospital, Hachioji, Tokyo 192-0032; ${ }^{4}$ Department of General Thoracic Surgery, \\ Saitama Medical Center, Kawagoe, Saitama 350-8550; ${ }^{5}$ Department of Surgery, Teikyo University \\ School of Medicine, Itabashi-ku, Tokyo 173-8605; Departments of ${ }^{6}$ General Thoracic Surgery, and \\ ${ }^{7}$ Pathology, Tokai University School of Medicine, Isehara, Kanagawa 259-1193, Japan
}

Received June 10, 2010; Accepted July 21, 2010

DOI: 10.3892/ol_00000147

\begin{abstract}
Expression of copper-transporting P-type adenosine triphosphatase A (ATP7A) is reportedly associated with platinum drug resistance in various types of solid tumors. However, the impact of ATP7A expression on platinum drug resistance in non-small cell lung cancer (NSCLC) has yet to be adequately elucidated. In vitro cisplatin (CDDP) sensitivity was investigated using the collagen gel-droplet embedded culture drug sensitivity test, and the ATP7A mRNA expression levels were assessed by real-time polymerase chain reaction in surgically resected specimens of NSCLC. The relationship between the ATP7A expression levels and the in vitro CDDP sensitivity was then evaluated. The ATP7A mRNA expression levels in the CDDP-resistant tumors were significantly higher than those in the CDDP-sensitive tumors ( $\mathrm{p}=0.0167$, Mann-Whitney U test). In conclusion, the results suggest that evaluation of ATP7A expression is useful as a marker for cisplatin chemoresistance.
\end{abstract}

\section{Introduction}

Cisplatin (CDDP), an anticancer drug containing platinum, is widely used in the treatment of solid tumors, such as testicular, ovarian, cervical, bladder, head and neck, and non-small cell lung cancers (NSCLC) (1). CDDP has been used as a key drug for chemotherapy against NSCLC for more than 20 years.

Correspondence to: Dr Yoshimasa Inoue, Department of General Thoracic Surgery, Ikegami General Hospital, 6-1-19 Ikegami, Ota-ku, Tokyo 146-8531, Japan

E-mail: yoshimas@is.icc.u-tokai.ac.jp

Abbreviations: NSCLC, non-small cell lung cancer; CDDP, cisplatin; CD-DST, collagen gel-droplet embedded culture drug sensitivity test; PCR, polymerase chain reaction; GIR, growth inhibition rate

Key words: non-small cell lung cancer, cisplatin, drug resistance
However, the overall response rate to cisplatin used as a single agent is reported to be no more than $20 \%$ in patients with NSCLC (2). Furthermore, development of resistance to CDDP is common during treatment of NSCLC and is therefore a significant factor to be considered by clinical oncologists. Subsequently, exploration of a chemoresistance marker is crucial. The mechanisms underlying the development of CDDP resistance include decreased drug accumulation, enhanced detoxification and increased DNA repair efficiency. However, previous studies have been limited mainly to the in vitro or in vivo level. Additionally, no study has shown factors that have been validated as common contributors to clinical CDDP resistance and prognosis in NSCLC patients (1).

Copper-transporting P-type adenosine triphosphatase A (ATP7A) plays a significant role in copper distribution within cells. ATP7A is expressed in the intestinal epithelium as well as in most other tissues apart from the liver (3-7). Binding of $\mathrm{Cu}$ to ATP7A triggers highly regulated subcellular relocalization that involves movement from the basal position in the trans-Golgi network to the plasma membrane $(3,8)$. Defective function of ATP7A causes Menkes disease, and the pathology of Menkes disease reflects the inadequate mobilization of $\mathrm{Cu}$ from a number of tissues. Previous studies suggested that the copper export system also functions as an efflux transporter for platinum drugs. These studies also showed an association between ATP7A expression and resistance to platinum drugs in malignancies (9-11). However, the ATP7A expression level and its impact on CDDP resistance in NSCLC has yet to be adequately elucidated.

The present study aimed to investigate the predictive value of ATP7A gene expression for the in vitro chemosensitivity of NSCLC to CDDP using surgically resected specimens from patients with NSCLC.

\section{Materials and methods}

Study population. Eligible patients included those with a histologic diagnosis of NSCLC, and who had undergone 
Table I. Relationship between in vitro CDDP sensitivity and patient characteristics.

\begin{tabular}{lccc}
\hline & \multicolumn{3}{c}{ In vitro CDDP sensitivity } \\
\cline { 2 - 3 } Characteristics & $\mathrm{R}$ & $\mathrm{S}$ & P-value $^{\mathrm{b}}$ \\
\hline Age (mean $\pm \mathrm{SD}$, years) & $69 \pm 7$ & $68 \pm 8$ & 0.60 \\
Gender & & & \\
$\quad$ Male & 7 & 9 & 0.30 \\
Female & 4 & 1 & \\
Histology & & & \\
Adenocarcinoma & 7 & 2 & 0.08 \\
Non-adenocarcinoma $^{\mathrm{c}}$ & 4 & 8 & \\
\hline
\end{tabular}

In vitro $\mathrm{CDDP}$ sensitivity: $\mathrm{R}$, resistant and $\mathrm{S}$, sensitive. ${ }^{\mathrm{P}} \mathrm{P}$-value evaluated by the Mann-Whitney U test or Fisher's exact test as appropriate. ${ }^{\mathrm{N}}$ Non-adenocarcinoma (i.e., squamous cell carcinoma, large cell carcinoma and poorly differentiated NSCLC).

Table II. Relationship between the ATP7A mRNA expression level and patient characteristics.

\begin{tabular}{lc}
\hline Characteristics & $\begin{array}{c}\text { ATP7A gene } \\
\text { expression level } \\
(\text { mean } \pm \text { SD })\end{array}$ \\
\hline
\end{tabular}

\begin{tabular}{lll}
\hline Age & & \\
$>70$ & $0.61 \pm 0.38$ & 0.90 \\
$\leq 70$ & $0.54 \pm 0.30$ & \\
Gender & & \\
Male & $0.87 \pm 0.42$ & 0.04 \\
Female & $0.46 \pm 0.25$ & \\
Histology & & \\
Adenocarcinoma & $0.74 \pm 0.38$ & 0.03 \\
Non-adenocarcinoma & \\
& $0.42 \pm 0.22$ &
\end{tabular}

aP-value evaluated by Mann-Whitney U test. ${ }^{\text {bNon-adenocarcinoma }}$ (i.e., squamous cell carcinoma, large cell carcinoma and poorly differentiated NSCLC).

surgical resection but had received no previous chemotherapy or radiotherapy. Patient specimens were subjected to a chemosensitivity test between 2005 and 2007 at the Teikyo University Hospital and Tokai University Hospital. Eligible patients who gave informed consent were recruited for the study. The patients consisted of 16 males and 5 females, ranging in age from 54 to 79 years (mean 68). A total of 9 tumors were confirmed to be adenocarcinomas, 8 were squamous cell carcinomas, 3 were large-cell carcinomas and 1 was confirmed to be poorly differentiated NSCLC.

In vitro chemosensitivity test. In vitro chemosensitivity was examined using the collagen gel-droplet embedded culture drug sensitivity test (CD-DST) method, as described by
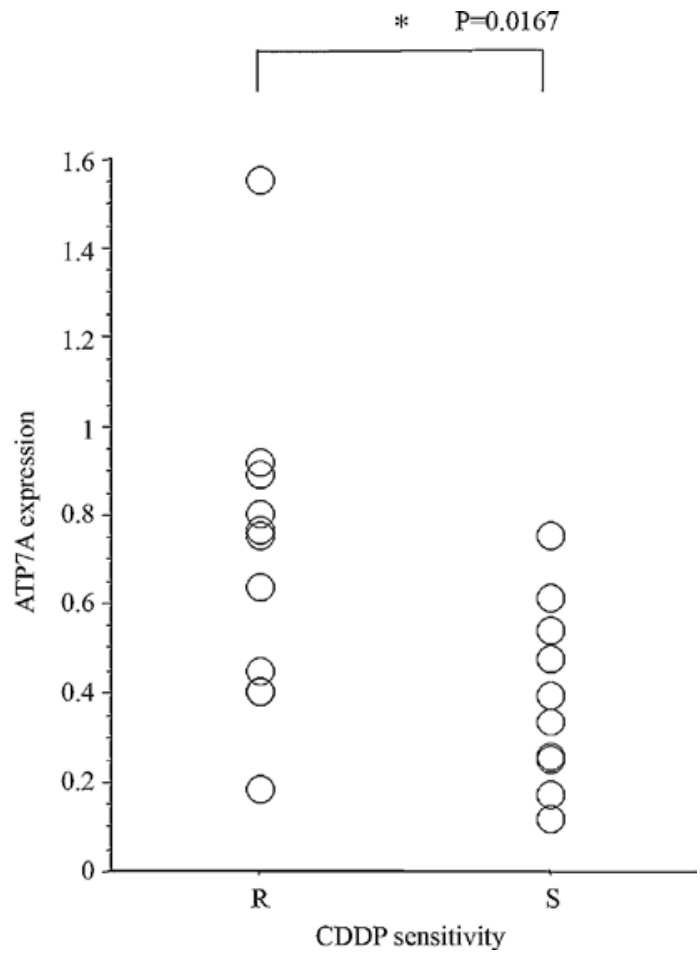

Figure 1. ATP7A mRNA expression level and in vitro cisplatin sensitivity.

Kobayashi et al $(12,13)$ and Kawamura et al $(14)$, with minor modifications. Briefly, surgically resected specimens were finely minced using a scalpel and digested in cell dispersion enzyme solution EZ (Nitta Gelatin Inc.). The dispersed cancer cells were then washed and filtered through a nylon mesh with a pore size of $200 \mathrm{~mm}$, collected by centrifugation, suspended in PCM-1 medium (Nitta Gelatin Inc.) and incubated in a $\mathrm{CO}_{2}$ incubator at $37^{\circ} \mathrm{C}$ for $24 \mathrm{~h}$. Viable cells were collected and re-suspended in reconstituted type I collagen solution with a final cell density of $1 \times 10^{5}$ cells $/ \mathrm{ml}$. Three drops of the collagen-cell mixture ( $30 \mathrm{ml} / \mathrm{drop})$ were placed in each well of a 6-well multiplate and allowed to gel overnight at $37^{\circ} \mathrm{C}$. Cisplatin (CDDP) (Bristol-Myers Squibb Inc.) was then added at a final concentration of $2 \mathrm{mg} / \mathrm{ml}$, and the plates were incubated for $24 \mathrm{~h}$. Following removal of the medium containing the anticancer drugs, each well was rinsed twice, overlaid with PCM-2 medium (Nitta Gelatin Inc.) and incubated for 7 days. At the end of the incubation period, the colonies were stained with neutral red $(50 \mathrm{mg} / \mathrm{ml}$, $3 \mathrm{~h}$ ). Each collagen droplet was then fixed with $10 \%$ neutral formalin buffer, washed in water, air-dried and quantified using imaging analysis. The in vitro sensitivity was expressed as the growth inhibition rate (GIR): $(1-\mathrm{T} / \mathrm{C}) \times 100(\%)$, where $\mathrm{T}$ is the total volume of the treated group and $\mathrm{C}$ is the total volume of the control group.

In this study, a tumor was judged as 'resistant' when the GIR was $<61 \%$ and 'sensitive' when the GIR was $\geq 61 \%$.

Cell line. The human colorectal cancer HCT8 cell line was obtained from Riken (Saitama, Japan). The cell line was cultured at $37^{\circ} \mathrm{C}$ in Dulbecco's modified Eagle's medium (containing $10 \%$ bovine serum) in a $5 \% \mathrm{CO}_{2}$ atmosphere. 
Quantitative evaluation of ATP7A $m R N A$ expression. Total RNA was extracted from the tumor samples and the cell line using the acid guanidinium thiocyanate-phenol-chloroform extraction method. Complementary DNA (cDNA) was synthesized from $1 \mu \mathrm{g}$ of total RNA as previously described (15-17).

Real-time PCR assays were run on an ABI PRISM 7000 Sequence Detection system (Perkin-Elmer Applied Biosystems) in accordance with the manufacturer's instructions and those of previously published studies (15-17). Briefly, a total volume of $50 \mu \mathrm{l}$ of a reaction mixture containing $1 \mu \mathrm{l}$ of the cDNA template, $25 \mu \mathrm{l}$ of TaqMan Universal PCR Master Mix (Perkin-Elmer Applied Biosystems) and $2.5 \mu \mathrm{l}$ of a primer probe mixture for ATP7A and $\beta$-actin was amplified using the following protocol: after initial denaturation $\left(2 \mathrm{~min}\right.$ at $95^{\circ} \mathrm{C}$ ), amplification was performed for 50 cycles of $15 \mathrm{sec}$ at $95^{\circ} \mathrm{C}$ and $60 \mathrm{sec}$ at $60^{\circ} \mathrm{C}$. The primer probe mixture for ATP7A (TaqMan ${ }^{\circledR}$ Gene Expression Assays, assay ID: Hs00163707_m1) and $\beta$-actin (human ACTB, 4310881E) (both from Perkin-Elmer Applied Biosystems) were purchased as part of the commercial provider's kit.

To precisely quantify the ATP7A gene transcripts, $\beta$-actin transcripts were used as a quantitative control, and each sample was normalized based on its $\beta$-actin transcript content. Standard curves for ATP7A and $\beta$-actin mRNA were generated using serially diluted solutions $(1 / 5,1 / 25,1 / 125$ and $1 / 625)$ of HCT8 cDNA. After determination of the threshold cycle $(\mathrm{Ct})$ which was defined as the PCR cycle number at which point the fluorescent intensity exceeded the threshold, the target gene expression level was calculated using the standard curve, and the quantitative normalization of cDNA in each sample was performed using the expression of the $\beta$-actin gene as an internal control. Finally, the ATP7A mRNA levels were represented as a ratio to the $\beta$-actin mRNA levels. Real-time PCR assays were conducted in duplicate on one dish for each sample, and the mean value was used to calculate the mRNA expression levels.

Statistical analysis. Categorical variables were analyzed using the Fisher's exact test. Continuous variables were compared using the Mann-Whitney $\mathrm{U}$ test. All reported P-values were two-sided. $\mathrm{P}<0.05$ was considered to be statistically significant.

\section{Results}

In vitro chemosensitivity test. The GIR values ranged from 0 to $68.6 \%$ (mean \pm standard deviation, $38.0 \pm 18.4 \%$ ). According to the protocol described in Materials and methods, 11 tumors were judged as 'resistant (R)' to CDDP, while the remaining 10 tumors were judged as being 'sensitive (S)' to CDDP.

No significant correlation was observed between the in vitro CDDP sensitivity and any of the clinical patient characteristics, including age, gender and histology (Table I).

ATP7A mRNA expression. The ATP7A mRNA expression levels varied from 0.12 to $1.55(0.56 \pm 0.33)$. Table II shows the relationship between the ATP7A expression levels and the clinical patient characteristics, including age, gender and histology. No significant correlation was observed between the ATP7A mRNA expression level and age $(\mathrm{p}=0.90$, MannWhitney U test).
The ATP7A mRNA expression level in the male group was significantly higher than that in the female group $(\mathrm{p}=0.04$, Mann-Whitney U test), and the ATP7A mRNA expression level in the adenocarcinoma group was significantly higher than that in the non-adenocarcinoma group ( $\mathrm{p}=0.03$, MannWhitney U test).

Relationship between ATP7A expression and CDDP sensitivity. The difference in the ATP7A mRNA expression level between the CDDP-resistant ( $\mathrm{R}$ group, $\mathrm{n}=11$ ) and CDDPsensitive tumors ( $\mathrm{S}$ group, $\mathrm{n}=10)$ was evaluated. The ATP7A mRNA expression levels in the $\mathrm{R}$ group were significantly higher than those in the $\mathrm{S}$ group $(\mathrm{p}=0.017$, Mann-Whitney $\mathrm{U}$ test; Fig. 1).

\section{Discussion}

ATP7A expression was reported to be associated with the sensitivity of ovarian carcinoma cells to platinum drugs $(9,10)$. Overexpression of ATP7A in ovarian carcinoma cells has been shown to be associated with higher levels of platinum drug accumulation, Additionally, ATP7A-overexpressing cells exhibit a significantly enhanced degree of resistance to platinum drugs (10). Analysis of the expression of ATP7A in ovarian carcinoma patients before and after treatment with a platinum drug-containing regimen demonstrated that in certain patients, treatment caused an enrichment of ATP7A-expressing cells in the tumors, resulting in a poor patient outcome (9). However, the ATP7A expression levels and their clinical significance in NSCLC have yet to be adequately elucidated.

The present study examined the association between the ATP7A mRNA expression levels and in vitro chemosensitivity to CDDP, using surgically resected specimens of NSCLC. The results revealed significantly higher expression levels of ATP7A mRNA in the CDDP-resistant tumors than in the CDDP-sensitive tumors.

Little is known regarding the differences in the ATP7A expression levels according to gender and histological subtype in NSCLC patients. In this study, significant correlations between the ATP7A expression levels and gender and histological subtypes were observed. Further study is needed to confirm and clarify the clinicopathological significance of this observation.

In conclusion, although the data presented in this study were based only on an in vitro assay, our results suggest that the ATP7A gene expression level is correlated with resistance to CDDP in NSCLC and that the ATP7A expression level may be a useful marker of chemoresistance to cisplatin.

\section{References}

1. Perez RP: Cellular and molecular determinants of cisplatin resistance. Eur J Cancer 34: 1535-1542, 1998.

2. Tiseo M, Franciosi V, Grossi F and Ardizzoni A: Adjuvant chemotherapy for non-small cell lung cancer: ready for clinical practice? Eur J Cancer 42: 8-16, 2006.

3. Terada K, Nakako T, Yang XL, et al: Restoration of holoceruloplasmin synthesis in LEC rat after infusion of recombinant adenovirus bearing WND cDNA. J Biol Chem 273: 1815-1820, 1998.

4. Chelly J, Tumer Z, Tonnesen T, et al: Isolation of a candidate gene for Menkes disease that encodes a potential heavy metal binding protein. Nat Genet 3: 14-19, 1993. 
5. Mercer JF, Livingston J, Hall B, et al: Isolation of a partial candidate gene for Menkes disease by positional cloning. Nat Genet 3: 20-25, 1993.

6. Vulpe C, Levinson B, Whitney S, Packman S and Gitschier J: Isolation of a candidate gene for Menkes disease and evidence that it encodes a copper-transporting ATPase. Nat Genet 3: 7-13, 1993.

7. Safaei R, Holzer AK, Katano K, Samimi G and Howell SB: The role of copper transporters in the development of resistance to $\mathrm{Pt}$ drugs. J Inorg Biochem 98: 1607-1613, 2004.

8. Petris MJ, Strausak D and Mercer JF: The Menkes copper transporter is required for the activation of tyrosinase. Hum Mol Genet 9: 2845-2851, 2000.

9. Samimi G, Varki NM, Wilczynski S, Safaei R, Alberts DS and Howell SB: Increase in expression of the copper transporter ATP7A during platinum drug-based treatment is associated with poor survival in ovarian cancer patients. Clin Cancer Res 9: 5853-5859, 2003.

10. Samimi G, Safaei R, Katano K, et al: Increased expression of the copper efflux transporter ATP7A mediates resistance to cisplatin, carboplatin, and oxaliplatin in ovarian cancer cells. Clin Cancer Res 10: 4661-4669, 2004.

11. Safaei R, Katano K, Samimi G, et al: Cross-resistance to cisplatin in cells with acquired resistance to copper. Cancer Chemother Pharmacol 53: 239-246, 2004.
12. Kobayashi H, Higashiyama M, Minamigawa $\mathrm{K}$, et al: Examination of in vitro chemosensitivity test using collagen gel droplet culture method with colorimetric endpoint quantification. Jpn J Cancer Res 92: 203-210, 2001.

13. Kobayashi H: Development of a new in vitro chemosensitivity test using collagen gel droplet embedded culture and image analysis for clinical usefulness. Recent Results Cancer Res 161: 48-61, 2003.

14. Kawamura M, Gika M, Abiko T, et al: Clinical evaluation of chemosensitivity testing for patients with unresectable non-small cell lung cancer (NSCLC) using collagen gel droplet embedded culture drug sensitivity test (CD-DST). Cancer Chemother Pharmacol 59: 507-513, 2007.

15. Nakagawa $\mathrm{T}$, Inoue $\mathrm{Y}$, Kodama $\mathrm{H}$, et al: Expression of coppertransporting P-type adenosine triphosphatase (ATP7B) correlates with cisplatin resistance in human non-small cell lung cancer xenografts. Oncol Rep 20: 265-270, 2008.

16. Nishi M, Abe Y, Fujimori S, et al: The modifier subunit of glutamate cysteine ligase relates to cisplatin resistance in human small-cell lung cancer xenografts in vivo. Oncol Rep 14: 421-424, 2005.

17. Fujimori S, Abe Y, Nishi M, et al: The subunits of glutamate cysteine ligase enhance cisplatin resistance in human non-small cell lung cancer xenografts in vivo. Int J Oncol 25: 413-418, 2004. 